\title{
CORRECTION
}

Check for updates

Cite this: Phys. Chem. Chem. Phys. 2021, 23, 14109

DOI: $10.1039 / \mathrm{d} 1 \mathrm{cp} 90124 \mathrm{a}$

rsc.li/pccp

\section{Correction: Thermoelectric properties of CZTS thin films: effect of $\mathrm{Cu}-\mathrm{Zn}$ disorder}

\author{
E. Isotta, (D)*a U. Syafiq, (D) $\star^{a b}$ N. Ataollahi, (D) a A. Chiappini, ${ }^{c}$ C. Malerba, ${ }^{d}$ S. Luong, ${ }^{e}$ \\ V. Trifiletti, ${ }^{e}$ O. Fenwick, (D) ${ }^{e}$ N. M. Pugno (D) aef and P. Scardi (D)*a
}

Correction for 'Thermoelectric properties of CZTS thin films: effect of Cu-Zn disorder' by E. Isotta et al., Phys. Chem. Chem. Phys., 2021, DOI: 10.1039/d1cp01327k.

The authors would like to correct the author list in ref. 17 of the published article. The amended citation details are as shown in ref. 1 below.

The Royal Society of Chemistry apologises for these errors and any consequent inconvenience to authors and readers.

\section{References}

1 E. Isotta, C. Fanciulli, N. M. Pugno and P. Scardi, Effect of the order-disorder transition on the Seebeck coefficient of nanostructured thermoelectric $\mathrm{Cu}_{2} \mathrm{ZnSnS}_{4}$, Nanomaterials, 2019, 9, 762.

\footnotetext{
${ }^{a}$ Department of Civil, Environmental and Mechanical Engineering, University of Trento, Trento, Italy. E-mail: eleonora.isotta@unitn.it, paolo.scardi@unitn.it, muhammad.mustaffa@unitn.it

${ }^{b}$ Solar Energy Research Institute, National University of Malaysia (SERI-UKM), 43600 Bangi, Selangor, Malaysia

${ }^{c}$ IFN-CNR CSMFO Lab. and FBK Photonics Unit, Trento, Italy

${ }^{d}$ Italian National Agency for New Technologies, Energy and Sustainable Economic Development (ENEA), Rome, Italy

${ }^{e}$ School of Engineering and Materials Science, Queen Mary University of London, London, UK

${ }^{f}$ Department of Civil, Environmental and Mechanical Engineering, Laboratory of Bio-inspired, Bionic, Nano, Meta Materials \& Mechanics, University of Trento, Trento, Italy
} 